\title{
Journal of Human Sport and Exercise online
}

\author{
J. Hum. Sport Exerc. \\ Official Journal of the Area of Physical Education and Sport. \\ Faculty of Education. University of Alicante. Spain
}

ISSN 1988-5202 / DOI 10.4100/jhse

An International Electronic Journal

Volume 4 Number 2 July 2009

\section{Research Article}

\section{BENEFICIAL EFFECTS OF THE WHOLE-BODY CRYOTHERAPY ON SPORT HAEMOLYSIS}

\author{
Giuseppe Banfi ${ }^{1,2} \cup$, Gianluca Melegati ${ }^{2,3}$, Alessandra Barassi ${ }^{1,4}$, Gianvico Melzi d'Eril ${ }^{1,4}$ \\ ${ }^{1}$ School of Medicine, University of Milan, Italy. ${ }^{2}$ IRCCS Galeazzi, Milan, Italy. ${ }^{3}$ Italian Rugby \\ Federation, Rome, Italy. ${ }^{4}$ Laboratorio Analisi, Ospedale San Paolo, Milan, Italy
}

Received: 28 November 2008; received in revised form: 15 February 2009; accepted: 20 March 2009

\begin{abstract}
Background. Sport's anemia is a common risk for athletes. The principal source of an accelerated turnover of the erythrocytes in sportsmen is the intravascular hemolysis. This phenomenon is induced by mechanical breakage for impact of feet and muscular contractions, but also by osmotic changes causing membrane fragility, typically evident after exercise, when free radicals are increased. Wholebody cryotherapy (WBC) covers a wide range of therapeutic applications and consists of briefly exposing the body to extremely cold air. In sports medicine, WBC is used to improve recovery from muscle injury; however, empirical studies on its application to this area are lacking. Design and Methods. We recruited ten rugby players of the Italian National Team. In these athletes we measured hematological parameters, before including mean sphered cell volume (MSCV) by means of Coulter LH750, besides of haptoglobin, and after WBC. The subjects underwent five sessions on alternate days once daily for one week. During the study period, the training workload was the same as that of the previous weeks. Results. We observed in the athletes increase of haptoglobin and an increase of MSCV after the treament period. Conclusions. WBC reduces sports haemolysis, as judged from MSCV and haptoglobin data, supported from other haematological values, as well as the absence of mean corpuscolar volume and reticulocytes increase. The treatment is useful to prevent the physiological impairments derived from sport haemolysis.
\end{abstract}

Key words: Haemolysis, athletes, MSCV, haptoglobin, rugby

Reference Data: Banfi G, Melegati G, Barassi A, d'Eril GM. Beneficial effects of the whole-body cryotherapy on sport haemolysis. J. Hum. Sport Exerc. 2009; 4(2):189-193.

Corresponding author. School of Medicine, University of Milan, via Festa del Perdono 7 - 20122, Milan, Italy.

Email: giuseppe.banfi1@unimi.it

(C) 2009 University of Alicante. Faculty of Education.

DOI:10.4100/jhse.2009.42.11 


\section{INTRODUCTION}

Whole-body cryotherapy (WBC) consists of brief exposure to extreme cold in a temperature-controlled chamber $\left(-110^{\circ} \mathrm{C}\right)$. It is applied to relieve pain and inflammatory symptoms caused by numerous disorders, particularly those associated with rheumatic conditions, and is recommended for the treatment of arthritis, fibromyalgia and ankylosing spondylitis. In sports medicine, WBC has gained wider acceptance as a method to improve recovery from muscle injury; however, no controlled studies have been published so far.

In sports medicine, WBC is also now popular and it is known for improving recovery from muscular traumas, although controlled studies have not been published. The treatment is not dangerous for lung function (Smolander et al., 2006), and did not decrease the antioxidant capacity (Dugué et al., 2005). We demonstrated that WBC does not enhance haematological values, as judged from concentrations of haemoglobin and of number of erythrocytes, reticulocytes, leukocytes, and platelets (Banfi et al., 2008) and the treatment is beneficial for muscle metabolism and, contemporarily, not dangerous for immunological system (Banfi et al., 2008). We demonstrated that decreased levels of the haematological parameter mean sphered cell volume (MSCV) are related to sports haemolysis (Banfi et al., 2007).

In general, WBC does not appear to be harmful; indeed, it may be beneficial for athletes since prompt recovery from muscle injury is a primary concern for both athletes and sports physicians alike. Despite the wealth of literature on rehabilitation techniques, published data on WBC in rehabilitation programs are scarce. Studying the effects of WBC can have practical value not only for many physiological and clinical purposes, but also for determining clinical significance in the context of antidoping testing, since techniques that accelerate recovery may be classified as prohibited. Furthermore, post-WBC treatment changes in biochemical and hematological parameters could result outside the threshold range imposed by sports federations and official control agencies, with the athletes classified as being doped, or could be interpreted as an attempt to mask changes caused by illicit treatment different from WBC.

The aim of this study was to determine whether WBC had a positive effect on eryhtrocyte metabolism, particularly during the recovery from exertional damage, which is characterized from haemolysis. Biochemical and immunological markers were measured at baseline and after one week of WBC treatment (five once daily sessions) in ten male rugby players selected randomly from the Italian National team.

\section{MATERIAL AND METHODS}

Ten male athletes (mean age $26 \pm 2.5$ years; mean body-mass index $27.5 \pm 2.3 \mathrm{~kg} / \mathrm{m} 2$ ) underwent once daily WBC treatment for five days (Monday, Tuesday, Wednesday, Friday, and Saturday) at the Olympic Rehabilitation Center of Spała (Poland). Wearing minimal clothing, the subjects were first exposed to very cold air $\left(30 \mathrm{~s}\right.$ at $\left.-60^{\circ} \mathrm{C}\right)$ then to extremely cold air $\left(2 \mathrm{~min}\right.$ at $\left.-110^{\circ} \mathrm{C}\right)$. They reported an improved sense of general well-being and no discomfort or disturbance. 
During the study period, the subjects continued with their regular training. The workload was the same as in the previous six weeks. Training consisted of three hours of daily exercises: one hour of maximal training in the morning, followed by one hour of submaximal effort, then one hour of submaximal training in the afternoon, in addition to conditioning exercises.

No illnesses occurred during the study period. Diet was controlled and identical to that of the previous six weeks.

The ten subjects were chosen randomly from the Italian National rugby team (30 athletes). All gave informed consent to the study protocol. Blood samples were drawn by Vacutainer tubes at 8 a.m. on the first day of treatment (Monday) and then at the end of treatment on the following Monday. The time period from the last intense training session was the same for both blood drawings.

The sera were separated within 3 hours from drawing and stored at $-20^{\circ} \mathrm{C}$ until assayed. The haematological tests were performed three hours from drawing on Coulter LH750 (Coulter, Hialeah, USA), regularly controlled and calibrated. Haptoglobin was measured on BN Prospec (Dade, Marburg, Germany), regularly controlled and calibrated. Coefficients of variation were $<2 \%$ for haematological values and $<4 \%$ for haptoglobin.

Statistical analysis was performed by using paired $t$ test on MedCalc program (Mariawerke, Belgium). Statistical significance was set at $\mathrm{p}<0.05$.

\section{RESULTS}

Mean concentration of haptoglobin before WBC was $56.6 \mathrm{mg} / \mathrm{L}(\mathrm{SD}: 33.5)$ and $75.2 \mathrm{mg} / \mathrm{L}$ (SD:40.7) after the treatment ( $\mathrm{p}<0.05)$. MSCV increased from $84.6 \mathrm{fL}$ (SD:3.4) to $87.6 \mathrm{fL}$ ( $\mathrm{SD}: 4.4 ; \mathrm{p}<0.05)$.

The number of leukocytes, erythrocytes, and platelets was not modified after the treatment. Haemoglobin significantly decreased, when haematocrit was unmodified. It is particularly interesting the data about classical erythrocytes parameters. Mean corpuscular volume was unmodified ( $89.5 \pm 3.7 \mathrm{fL}$ before, $89.4 \pm 3.9$ after $\mathrm{WBC})$, whereas statistical significance was demonstrated $(\mathrm{p}<0.01)$ for mean corpuscular haemoglobin (from $31.2 \pm 1.5$ to $30.5 \pm 1.3 \mathrm{pg}$ ) and for mean corpuscular haemoglobin concentration (from $34.9 \pm 0.4$ to $34.2 \pm 0.3 \mathrm{~g} / \mathrm{dL}$ ), according to the decrease of total haemoglobin. Reticulocytes were unmodified.

\section{DISCUSSION}

The athletes should be accurately monitored by means of haematological parameters for avoiding risk of sports' anemia, linked to various sources: haemodilution during the initial training, insufficient iron intake, but, in particular, to iron loss due to intravascular haemolysis, typically occurring in exercise. Modern haematological systems supply a wide series of RBC and Ret parameters with high accuracy and precision, but clinical validity and application are not completely known for some of these "new" parameters. Iron turnover is accelerated in athletes because of haemolysis, particularly in endurance sports and when an impact of the feet on surfaces happen, inducing mechanical damage of RBC. Thus, haemolysis could be considered the principal source of increased RBC turnover and possible risk of sports' anemia, when destroyed RBC are not promptly and adequately recovered by the bone marrow production and release (Telford et al., 2003). 
Haemolysis should be diagnosed by the decrease of haptoglobin, which captures free haemoglobin released from destroyed RBC. Haptoglobin is, however, an acute phase protein and its serum concentration could be influenced by pathologies and also by physical exercise: in the ultramarathon the protein increased after 4 and 11 days out of 16 days of race (Fallon et al., 1999); haptoglobin concentration has been found to be depressed after marathon running (Davidson et al., 1987). The increase of haptoglobin does not exclude the intravascular haemolysis, but means that the intensity of the acute phase reaction is wider than haemolysis phenomenon. Moreover, haptoglobin shows high biological variability $(7.9 \%$ interindividual and $20 \%$ intraindividual) with an index of individuality of 0.72 (Maes et al., 1995). This means that the values should be always interpreted by comparison with basal ones, but in athletes it could be difficult because of traumas, inflammation, and drugs taken for these reasons. The use of MSCV simply obtained in $\mathrm{CBC}$ can be precious for demonstrating haemolysis in athlete, avoiding a series of further tests and also unnecessary instrumental investigations, as we demonstrated in top-level rugby players during a whole season (Banfi et al., 2007).

In conclusion, WBC reduces sports haemolysis, as judged from MSCV and haptoglobin data, supported from other haematological values, as well as the absence of mean corpuscolar volume and reticulocytes increase. The treatment is useful to prevent the physiological impairments derived from sport haemolysis.

\section{REFERENCES}

1. BANFI G, DI GAETANO N, SIMON LOPEZ R, MELEGATI G. Decreased mean sphered cell volume values in top-level rugby players are related to the intravascular hemolysis induced by exercise. Lab Hematol. 2007; 13:103-7. [Abstract] [Back to text]

2. BANFI G, KRAJEWSKA M, MELEGATI G, PATACCHINI M. Effects of the whole body cryotherapy on haematological values in athletes. $\mathrm{Br} J$ Sports Med. 2008; 42:558. [Abstract] [Back to text]

3. BANFI G, MELEGATI G, BARASSI A, DOGLIOTTI G, MELZI D'ERIL G, DUGUÉ B, CORSI MM. Effects of whole-body cryotherapy on serum mediators of inflammation and serum muscle enzymes in athletes. Thermal Biol 2009 (in press). [Full text] [Back to text]

4. DAVIDSON RJL, ROBERTSON SD, GALEA G, MAUGHAM RJ. Hematological changes associated with marathon running. Int $J$ Sports Med. 1987; 8:19-25. [Abstract] [Back to text]

5. DUGUÉ B, SMOLANDER J, WESTERLUND T, OKSA J, NIEMINEN R, MOILANEN E, MIKKELSON M. Acute and long-term effects of winter swimming and whole-body cryotherapy on plasma antioxidative capacity in healthy women. Scand J Clin Lab Invest. 2005; 65:395-402. [Abstract] [Back to text]

6. FALLON KE, SIVYER G, SIVYER K, DARE A. Changes in haematological parameters and iron metabolism associated with a 1600 kilometre ultramarathon. $\mathrm{Br} J$ Sports Med. 1999; 33:27-31. [Abstract] [Back to text]

7. MAES M, COOREMAN E, DELANGHE J, SCHOUPE S, WAUTERS A, NEELS H, et al. Components of biological variation in plasma haptoglobin: relationship to plasma fibrinogen and immune variables, including interleukin-6 and its receptor. Clin Chim Acta. 1995; 239:23-35. [Abstract] [Back to text]

8. SMOLANDER J, WESTERLUND T, UUSITALO A, DUGUÉ B, OKSA J, MIKKELSON M. Lung function after acute and repeated exposures to extremely cold 
air (-110 degrees C) during whole-body cryotherapy. Clin Physiol Funct Imaging. 2006; 26:232-4. [Abstract] [Back to text]

9. TELFORD RD, SLY GJ, HAHN AG, CUNNINGHAM RB, BRYANT C, SMITH JA. Footstrike is the major cause of hemolysis during running. J Appl Physiol. 2003; 94:38-42. [Full text] [Back to text] 